We welcome letters to the Editor concerning articles which have recently been published. Such letters will be subject to the usual stages of selection and editing; where appropriate the authors of the original article will be offered the opportunity to reply.

Letters should normally be under $\mathbf{3 0 0}$ words in length, doublespaced throughout, signed by all authors and fully referenced. The edited version will be returned for approval before publication.

(C)2007 British Editorial Society of Bone and Joint Surgery \$2.00 J Bone Joint Surg [Br] 2007;89-B:1673-5.

\section{Survival and clinical outcome of SB Charité III disc replacement for back pain}

Sir,

We read with interest the article by Ross et $\mathrm{al}^{1}$ in the June 2007 issue entitled 'Survival and clinical outcome of SB Charité III disc replacement for back pain'. Scientific interpretation flaws throughout this paper cast significant doubt on the validity of the presented outcomes.

The clinical improvements observed in this report were described as "below the clinical significant threshold". Clinical improvements represent changes against established, preoperative baselines. In this study, only $48 \%$ of pre-operative data was available, indicating that no clear baseline could effectively be drawn. In addition, the clinically significant threshold used herein was set by the authors. Published literature refers to a minimal clinically important difference (MCID) of ten points for Oswestry Disability Index (ODI) scores and $18 \mathrm{~mm}$ to $19 \mathrm{~mm}$ for the visual analogue scale. According to this definition, the improvement noted in this paper met the MCID for ODI.

Mathematical inconsistencies throughout the presented data further bring into question the overall clinical relevance of this research. For example, the Kaplan-Meier curve for device failure (Fig. 2) does not match the device failure table (Table IV), in which the last noticeable failure was reported at 106 months. In the Kaplan-Meier curve, no change is reported at 106 months but a change of approximately $20 \%$ is noted between 123 and 134 months post-operatively. Change patterns in this Kaplan-Meier curve also suggest that very few patients were available for follow-up after 79 months.

Finally, implant failures noted herein were described by others as a result of polymer degradation due to air sterilisation. This issue is long since solved and does not apply to the current Charité artificial disc.

It is unfortunate that they did not report on the accuracy of the surgical positioning of the prosthesis within the disc space, a critical factor in long-term clinical success. Thus, the only effective conclusions from this study are that, at a follow-up of approximately seven years, $94.7 \%$ device survivorship was observed, and roughly $80 \%$ of patients maintained motion at the index level. doi:10.1302/0301-620X.89B12.20450
R. D. GUYER, MD, FAAOS, Neurosurgeon

S. L. BLUMENTHAL, MD, FAAOS

Texas Back Institute,

Texas, USA.

1. Ross R, Mirza AH, Norris HE, Khatri M. Survival and clinical outcome of SB Charité III disc replacement for back pain. J Bone Joint Surg [Br]2007;89-B:785-9.

\section{Authors' reply:}

Sir, We thank Dr Guyer and Dr Blumenthal for their comments and interest in our paper.

Contrary to his assertion, difficulty and complexity surrounds the definition of the minimal clinically important difference (MCID). Most studies have shown that the MCID should have a context-specific value - as in our study an Oswestry Disability Index (ODI) change of $15 \%$ - rather than a fixed number as Dr Guyer proposes. We chose the figure for ODI and visual analogue scale (VAS) scores since these are the quoted figures for the same studies which the FDA required of Guyer and his colleagues in this field. We are well aware of the published literature describing a MCID of ten points for ODI and MCID of $18 \mathrm{~mm}$ to $19 \mathrm{~mm}$ for VAS $^{1}$ as noted by Dr Guyer.

A recent study published in November $2006^{2}$ showed that for lumbar discectomy, a minimum 27-point change in ODI would be classed as acceptable, whilst, for a decompression, 16 points were needed, and a fusion required a 13-point change. For our data analysis we stipulated a change of $15 \%$ ( 7.5 points), less than Dr Guyer's suggestion of a 10-point ODI change being clinically important. Thus, if we had taken Dr Guyer's figure then the results would be even worse! If he is confusing points with percentages, i.e. $10 \%$ rather than our stated $15 \%$, then essentially he is lowering the bar and we disagree that such a change is meaningful in a clinical context.

Failure of the polyethylene core implant is not unique to our study and has been described by others. To discount this finding as due to outdated sterilisation technique is inappropriate. Indeed, polyethylene wear and fracture has been noted in Charite discs implanted even after newer sterilisation techniques minimising oxidation were employed. What is more important is the shelf life of the prosthesis plus its packaging. This is not a valid criticism and we refer readers to Kurtz et al.

There are no "mathematical inconsistencies throughout the paper", as suggested. The duration of the series is clearly stated: January 1990 to December 2000. The Kaplan-Meier curve in Figure 2 shows an attrition of around $10 \%$ for that period (ten years/120 months). This is consistent with the 12 of 123 patients in Table IV. The remainder of that curve takes us up to the period when the study was undertaken. It predicts how many more failures will occur from this cohort during the period up to 2003 . That prediction has regrettably proved to be correct. In the last two years, six more implants have been removed and further 
removals are planned for this year. This pattern seems to fit with the experience of van Ooij et al. ${ }^{4}$

The comment on accuracy of positioning is most relevant. There is a considerable variation in where this implant is finally embedded. Improvement in the understanding of surgical technique and instrumentation has helped to achieve some improvement in the senior author's series. Nevertheless, there is a fundamental design issue in this prosthesis with respect to the posteriorly placed "teeth" which frequently impinge on bone, preventing further backward placement of the prosthesis. Only repositioning of these teeth can overcome this, a suggestion made to Waldemar-Link many times by the senior author. Currently this leads to the prosthesis being placed too anteriorly.

There is no doubt that prospective ongoing multicentre studies are required. To date, this study represents the largest cohort of patients undergoing this surgery in a single centre. Our results were independently analysed and until such a time as newer evidence to the contrary comes to light, we maintain that surgeons wishing to continue using this prosthesis, and patients agreeing to this surgery, should be aware of the risks demonstrated by this cohort.

doi:10.1302/0301-620X.89B12.20451

R. ROSS, MBChB, FRCS(Ed), FRACS, Spinal Surgeon

A. H. MIRZA, MBChB, MRCS(Ed)

H. E. NORRIS, BA(Hons), RGN

M. KHATRI, MS(Orth), FRCS(Tr \& Orth)

Hope Hospital,

Manchester, UK.

1. Hagg O, Fritzell P, Nordwall A, Swedish Lumbar Spine Society. The clinical importance of changes in outcome scores after treatment for chronic low back pain. Eur Spine J 203;12:12-20.

2. Tafazal SI, Sell PJ. Outcome scores in spinal surgery quantified: excellent, good, fair and poor in terms of patient-completed tools. Eur Spine J 2006;15:1653-60.

3. Kurtz SM, van Ooij A, Ross ERS, et al. Clinical significance of polyethylene oxidation for total disc arthroplasty. Trans ORS 2007;32:1130.

4. van Ooij A, Oner FC, Verbout AJ. Complications of artificial disc replacement: a report of 27 patients with the SB Charité disc. J Spinal Disord Tech 2003;16:369-83.

\section{Survival and clinical outcome of SB Charité III disc replacement for back pain}

Sir,

I read with interest the article by Ross et $\mathrm{al}^{1}$ in the June 2007 issue entitled 'Survival and clinical outcome of SB Charité III disc replacement for back pain' and feel that this study is, at best, level V evidence. However, methodological flaws fail to make this a clinically relevant case series. For example, a retrospective approach was used to analyse $52 \%$ of pre-operative data. This technique has been shown in the past to embellish good results and hyperbolise poor results, thus drawing into question the validity of the data presented in this paper.

An additional issue refers to the historical significance of the Charite III disc prosthesis (uncoated), the surgical technique pertaining to disc arthroplasty, and the surgical instruments available to the authors during the period under scrutiny. The uncoated prosthesis may have allowed for micromovements at the bone implant interface, possibly leading to macromovements such as subluxation of the endplate. In addition, the polyethylene core used since 2000 is no longer air-sterilised and thus has greater durability. As for the surgical technique, the transperitoneal approach described herein is renowned for all the complications recorded in Table V. These approach-related complications are minimised by the use of a retroperitoneal approach via a mid-line rectus splint. Furthermore, Ross et $\mathrm{al}^{1}$ excised the anterior and posterior annuluses. This greatly increases the instability of the motion segment, particularly with rotational instability. The surgical instruments (at the time developed by Link) were suboptimal by today's standards. Obtaining the correct position in the coronal and sagittal plane with these instruments was unreliable.

Finally, the paper does not attempt to distinguish between the data collected in single versus multi-level cases. This is critical in the context of the surgical technique described by the authors, as it predisposes to coronal instability.

This paper highlights the importance of precision diagnosis, a standardised modern surgical technique, state of the art instruments and prospective data collection to fairly assess the benefits of any new surgical technology.

doi:10.1302/0301-620X.89B12.20452

M. N. SCOTT-YOUNG, MBBS, FRACS, FAOrthA, Associate Professor of Faculty of Health Sciences and Medicine

Bond University,

Queensland, Australia.

1. Ross R, Mirza AH, Norris HE, Khatri M. Survival and clinical outcome of SB Charité III disc replacement for back pain. J Bone Joint Surg [Br] 2007;89-B:785-9.

\section{Authors' reply:}

Sir,

We would like to thank Dr Scott-Young for his interest in our paper.

Given that in back pain patients we frequently do not know why they have back pain and do not have the technology to measure anything meaningful, we would be interested in what he means by "precision diagnosis".

As described in our paper, the hydroxyapatite (HA) coating was introduced in Europe after 1995 and we acknowledge that the uncoated prosthesis may have been at higher risk of microand macromovement. Clearly, since 1995, we have used the HAcoated prosthesis. The aim of our paper was not to differentiate between the various guises of this prosthesis, nor to describe effects of changes in prosthesis design, but to describe our experience over a period of ten years in terms of patient outcome. However, we have not seen any published work confirming the beneficial effect - if any - of the HA coating on prosthetic survival.

With regard to surgical approach, we disagree with the opinion described by Dr Scott-Young. We are not aware of any definitive evidence to support either open anterior retroperitoneal or transperitoneal approaches to the spine. The surgical approach adopted may depend on various factors including previous abdominal or pelvic surgery and the surgeon's expertise.

Recent studies have shown complication rates of up to $14 \%$ in the retroperitoneal approach, ${ }^{1}$ which compares unfavourably with our overall complication rate. We acknowledge that in some hands, the transperitoneal approach may cause retrograde ejaculation, as seen in some studies. Our results show that the risk of retrograde ejaculation in our cohort $(3.1 \%)$ is less than described elsewhere $(13.3 \%)^{2}$ for the same procedure. In a study of the Acrodisc described by Fraser et al, ${ }^{3}$ the only retrograde ejaculation problem occurred in the retroperitoneal group.

With respect to Dr Scott-Young's comments on air sterilisation, we refer him to the latest literature and the work of Kurtz et al. ${ }^{4}$ 
Initially, the senior author produced flaps of the anterior annulus, and stitched these together at the completion of the prosthetic insertion. On many occasions, this was so flimsy that it was abandoned. How then to preserve the anterior annulus and insert a prosthesis by any anterior approach? Failure to release the posterior annulus will result in an inability to open the disc space in a parallel fashion, a crucial step in any disc replacement. Failure to remove the posterior annulus may also leave vascular and neural elements which are important in the pain generation sequence. No reference is quoted to support the assertion that removing these structures increases rotational instability, but even if it did so then one of the criticisms of all ball and socket devices is their lack of ability to restore physiological stiffness to the segment. Obtaining the correct position in the coronal and sagittal planes is dependent on so many other factors besides instrumentation, that to suggest an upgrade in instrumentation has solved the myriad problems associated with this device is facile. The experience of this prosthesis has led us to realise that prosthetic design, surgical approach and instrumentation should all be considered as a package with any new prosthetic concept. This was certainly not the case with this prosthesis.
What cannot be overlooked is the fact that an unacceptably high proportion of patients, despite meticulous surgical technique, required revision surgery or suffered persistent pain postoperatively. If our poor results are hyperbolised by the study method let Dr Scott-Young provide us with his own study to prove us at fault, since he is clearly a Charité user. doi:10.1302/0301-620X.89B12.20453

R. ROSS, MBChB, FRCS(Ed), FRACS, Spinal Surgeon

A. H. MIRZA, MBChB, MRCS(Ed)

H. E. NORRIS, BA(Hons), RGN

M. KHATRI, MS(Orth), FRCS(Tr \& Orth)

Hope Hospital,

Manchester, UK.

1. Gumbs AA, Shah RV, Yue JJ, Sumpio B. The open anterior paramedian retroperitoneal approach for spine procedures. Arch Surg 2005;140:339-43.

2. Sasso RC, Kenneth Burkus J, LeHuec JC. Retrograde ejaculation after anterior lumbar interbody fusion: transperitoneal versus retroperitoneal exposure. Spine 203;28:1023-6.

3. Fraser RD, Ross ER, Lowery GL, Freeman BJ, Dolan M. AcroFlex design and results. Spine J 2004;4(6 Supp)|:245-51.

4. Kurtz SM, van Ooij A, Ross ERS, et al. Clinical significance of polyethylene oxidation for total disc arthroplasty. Trans ORS 2007;32:1130. 